\section{References}

1 Wolf JL, Schreiber DS. Viral gastroenteritis. Med Clin North Am 1982; 66:575-95.

'Rodriguez WJ, Kim HW, Brandt CD, Fletcher AB, Parrott RH. Rotavirus: a cause of nosocomial infection in the nursery. $\mathcal{F}$ Pediatr $1982 ; 101: 274-7$

"Ryder RW, McGowan JE, Jr, Hatch MH, Palmer EL. Reovirus-like agent as a cause of nosocomial diarrhoea in infants. F Pediatr 1977; $\mathbf{9 0}: 698-707$.

- Halvorsrud J, Orstavik I. An epidemic of rotavirus-associated gastroenteritis in a nursing home for the elderly. Scand F Infect Dis 1980; 12:161-4.

Pickering LK, Evans DG, Du Pont HL, Vollet JJ, Evans DJ, Jr. Diarrhea caused by shigella, rotavirus and giardia in day care centers: prospective study. F Pediatr $1981 ; 99: 51-6$.

"Kim HW, Brandt CD, Kapikian AZ, Wyatt RG, et al. Human reoviruslike agent infection. Occurrence in adult contacts of paediatric patients with gastroenteritis. FAMA $1977 ; 238: 404-7$.
7 Wyn-Jones AP, Lillington AW, Alzaka A. An investigation into the possible role of the family unit in the transmission of rotavirus infections of children. Public Health 1978;92:291-3.

${ }^{\star}$ Tufvesson B, Johnsson T, Persson B. Family infections by reo-like virus. Scand $\mathcal{f}$ Infect Dis 1977;9:257-61.

${ }^{9}$ Haug KW, Orstavik I, Kvelstad G. Rotavirus infections in families. Scand F Infect Dis 1978;10:265-9.

1" Schousboe M, Faoagali J. Rotavirus detection for the routine laboratory. NZ Med f $1981 ; 73: 113-5$

"Bradstreet CMP, Taylor CED. Technique of complement-fixation test applicable to the diagnosis of virus diseases. Monthly Bulletin of the Ministry of Health Laboratory Service 1962;21:69-104.

12. Rodriguez WJ, Kim HW, Brandt CD, Yolken RH, et al. Common exposure outbreak of gastroenteritis due to type 2 rotavirus with high secondary attack rate within families. F Infect Dis 1979;140:353-7.

(Accepted 27 May 1983)

\title{
Serum folate concentrations during pregnancy in women with epilepsy: relation to antiepileptic drug concentrations, number of seizures, and fetal outcome
}

\author{
V K HIILESMAA, K TERAMO, M-L GRANSTRÖM, A H BARDY
}

\begin{abstract}
Serum folate concentrations, blood counts, and antiepileptic drug concentrations were measured during 133 pregnancies of 125 women with epilepsy. There was an inverse correlation between serum folate concentrations and concentrations of phenytoin and phenobarbitone. The number of epileptic seizures during pregnancy showed no association with serum folate concentrations. No cases of maternal tissue folate deficiency or fetal damage attributable to low maternal serum folate were observed. Maternal serum folate concentrations for infants with structural birth defects, "fetal hydantoin syndrome," or perinatal death were similar to those for healthy babies. A low dose (100 to $1000 \mu \mathrm{g}$ daily) of folate supplement appeared sufficient for pregnant women with epilepsy despite the antifolic action of antiepileptic medication.
\end{abstract}

Monitoring folate concentrations in pregnant women with high serum concentrations of phenytoin or phenobarbitone is recommended.

\section{Introduction}

Folic acid is required for synthesis of DNA and is essential for the normal development of the human fetus. ${ }^{1}$ A deficiency of

First and Second Departments of Obstetrics and Gynaecology, Helsinki University Central Hospital, 00290 Helsinki 29, Finland V K HIILESMAA, MD, obstetrician

K TERAMO, MD, obstetrician and perinatologist

Children's Hospital, 00290 Helsinki 29, Finland

M-L GRANSTRÖM, MD, neuropaediatrician

Pitäjänmäki Epilepsy Research Centre, 00370 Helsinki 37, Finland A H BARDY, MD, neurologist

Correspondence to: Dr V K Hiilesmaa. folate has been suspected of causing damage to the fetus, particularly if operative in the early weeks of pregnancy. ${ }^{2}$ Treatment with antiepileptic drugs may result in lowered serum folate concentrations ${ }^{34}$ and even in megaloblastic anaemia. ${ }^{2}$ Epileptic women taking antiepileptic drugs may reasonably be expected to be at particular risk of folate deficiency during their pregnancies ${ }^{1}$; systematic investigations on this are, however, lacking.

We undertook a prospective study of epileptic women during pregnancy, with serial measurements of both folate and antiepileptic drug concentrations.

\section{Patients and methods}

A total of 139 epileptic women were followed up during 150 pregnancies. Eighty eight women had grand mal (tonic and clonic convulsive) seizures, 16 had psychomotor (temporal lobe) seizures, 19 both grand mal and psychomotor, 10 focal motor or sensory, and six other or unclassified. The patients recorded their seizures on a calendar, which was checked at each visit. Of the 150 mothers, 137 took combined vitamin tablets with an average daily content of $500 \mu \mathrm{g}$ (range 100 to $1000 \mu \mathrm{g}$ ) of folic acid from the sixth to the 16th week of pregnancy until parturition; 143 received oral iron supplementation. Of the 150 pregnancies, 17 were excluded because of inadequate fast (see below) or failures in obtaining the blood samples. Subsequently, 133 singleton pregnancies in 125 women remained for analysis. Of the 133, 60 mothers had entered the study by the end of the 16th week of pregnancy.

Serum and red cell folate was radioassayed by a competitive protein binding method ${ }^{5} 6$ at Medix Laboratories, Kauniainen, Finland. Values of serum folate above $4.0 \mathrm{nmol} / 1(1.8 \mathrm{ng} / \mathrm{ml})(2.5$ percentile $)$ were considered normal. Haemoglobin concentrations and mean cell volume were measured with a Coulter $S$ counter. Serum phenytoin and phenobarbitone concentrations were measured by gas chromatography $^{7}$ and carbamazepine concentrations by spectrophotometry. ${ }^{8}$ Venous blood for folate and drug assessments was drawn between 1300 and 1500 hours, after a five to eight hour fast following breakfast and the last drug dose. There is evidence that antiepileptic drugs do not interfere with the radioassay of folate. ${ }^{9}$

Serum folate and haemoglobin concentration, mean cell volume, and serum concentrations of antiepileptic drugs were examined 
monthly. Red cell folate and whole blood smears were studied if the serum folate concentration was less than $4.5 \mu \mathrm{mol} / 1(2.0 \mathrm{ng} / \mathrm{ml})$, haemoglobin less than $10.5 \mathrm{~g} / \mathrm{dl}$, or mean cell volume greater than $96 \mathrm{fl}$.

The children were systematically examined for structural birth defects at birth and again at the age of 18 months. Features of the "fetal hydantoin syndrome" were recorded according to Hanson et al. ${ }^{10}$

Statistical assessment included logarithmic transformations of serum phenytoin, phenobarbitone, and folate concentrations to correct skewness, one way analysis of variance, and Pearson's correlation coefficients.

\section{Results}

Serum folate concentrations from the eighth to the sixteenth week of pregnancy showed an inverse correlation with concurrent serum phenytoin $(p=0.002)$ (fig $1(a)$ ) and phenobarbitone $(p=0.05)$ (fig $1(b)$ ) concentrations but no correlation with serum carbamazepine (fig $1(c)$ ) concentration. The same trend with weaker correlations was also observed during the second and third trimesters.
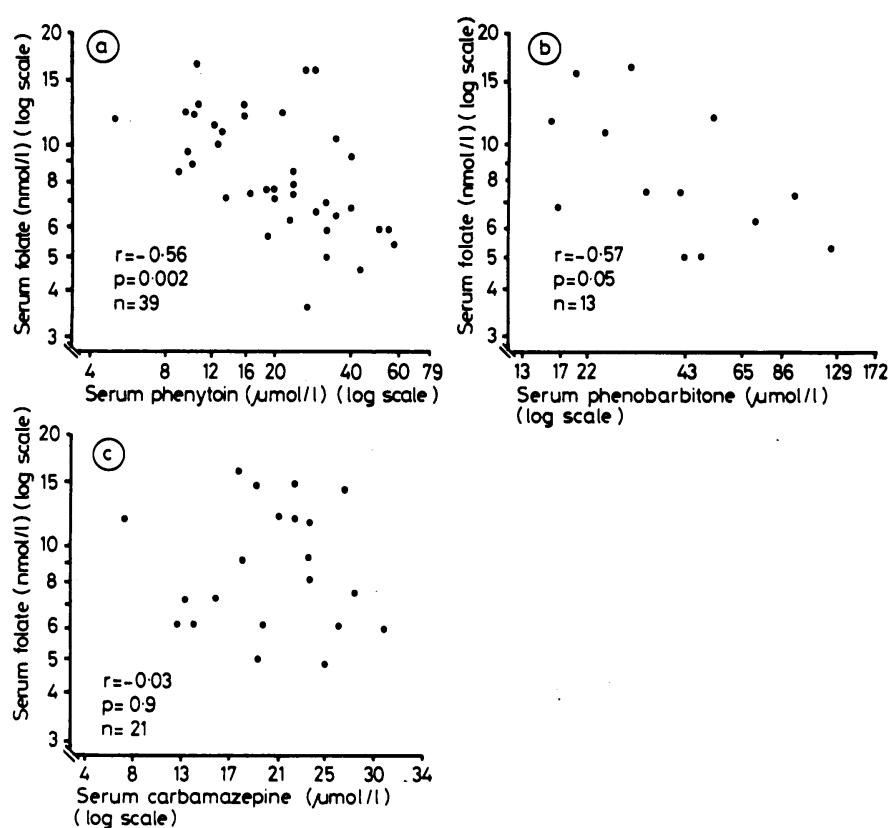

$(\log$ scale)

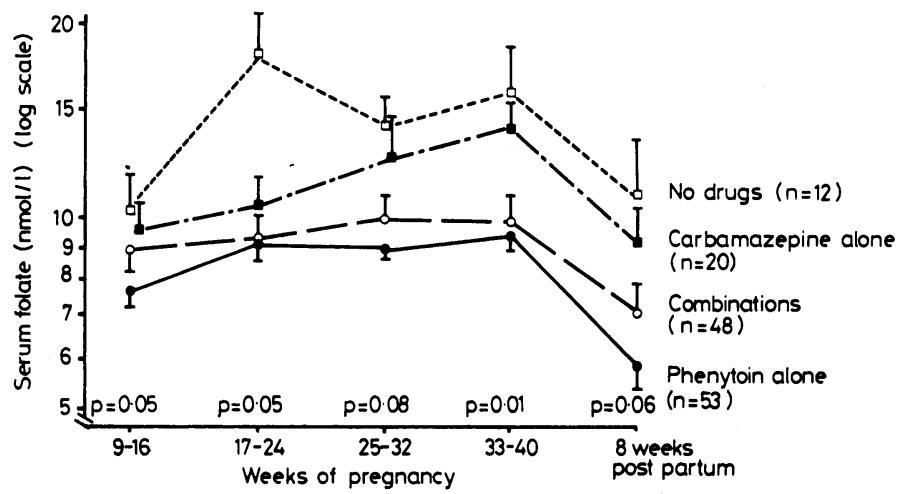

FIG 2-Serum folate concentrations during and after 133 pregnancies in epileptic women on four different regimens. All patients receiving phenobarbitone $(n-23)$ are in the group "combinations." Means and SEM of logserum folate concentrations are shown; $p$ values refer to one way analysis of variance.

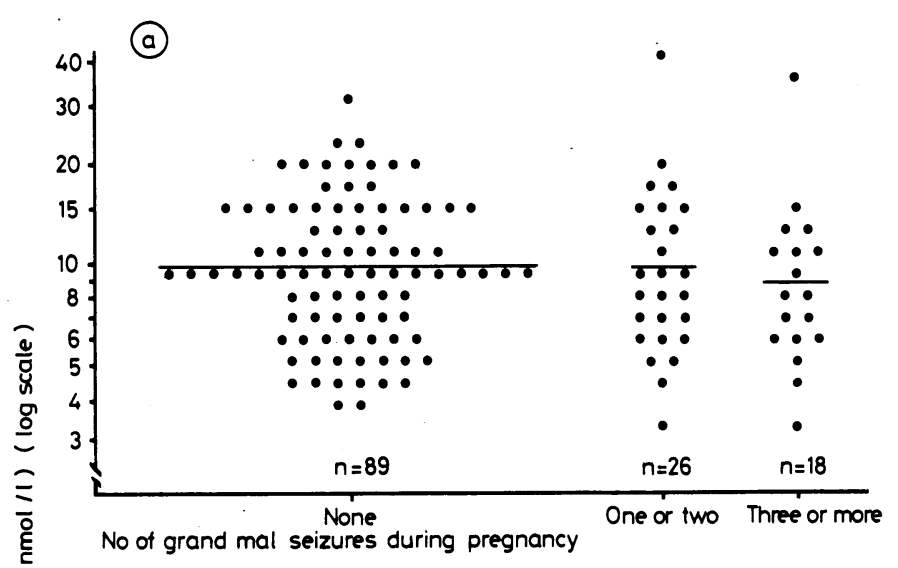

(b)

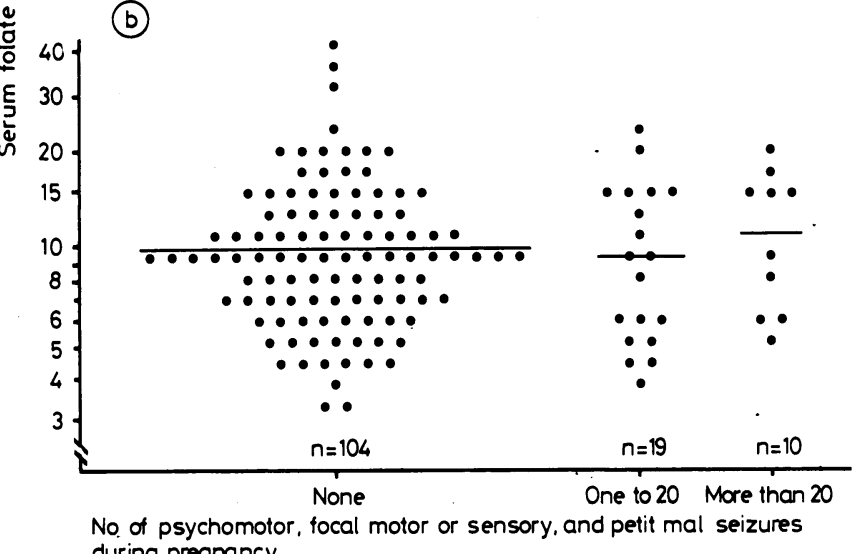

during pregnancy

FIG 3-Relation between serum folate during 133 pregnancies and number of (a) grand mal and $(b)$ other seizures. Serum folate concentrations are given as geometric means throughout pregnancy for each patient. One way analysis of variance: (a) $\mathrm{F}_{2: 130}-0.4, \mathrm{p}-0.7$. (b) $\mathrm{F}_{2: 130}=0.3 ; \mathrm{p}-0.7$. Differences between groups are not significant. ing any antiepileptic drugs showed the highest serum folate concentrations. Folate intake was similar in all groups. In all treatment groups the changes in serum folate concentration during pregnancy adhered to a common pattern-namely, an increase towards the end of pregnancy and a decrease after it.

Serum folate concentrations showed no association with the number of seizures during pregnancy (fig 3). Haemoglobin concentration and mean cell volume showed no association with types or concentrations of antiepileptic drugs. None of the 10 patients whose red cell folate and whole blood smears were examined showed tissue folate deficiency (red blood cell folate below $460 \mathrm{nmol} / 1(203 \mathrm{ng} / \mathrm{ml})$ or megaloblastic changes in the smear.

There were five perinatal deaths, nine infants with a structural birth defect, 10 with one or more features of the fetal hydantoin syndrome, and one with both a structural birth defect and fetal

hydantoin syndrome. Types and serum concentrations of antiepileptic drugs as well as serum folate concentrations (fig 4) in the mothers of these infants were similar to those in the rest of the series. The structural birth defects were: small ventricular septal defect (one), aplasia of the left lung (one), microcephaly (one), mild hypospadia (two), inguinal hernia (one), rudimentary sixth finger (one), and hip dislocation (three). No cases of oral clefts or neural tube defects were encountered. Fetal hydantoin syndrome appeared as facial dysmorphism and digital hypoplasia (three), facial dysmorphism only (six), and digital and nail hypoplasia (two). All cases of the syndrome were mild; no "complete" 10 ones were found. 


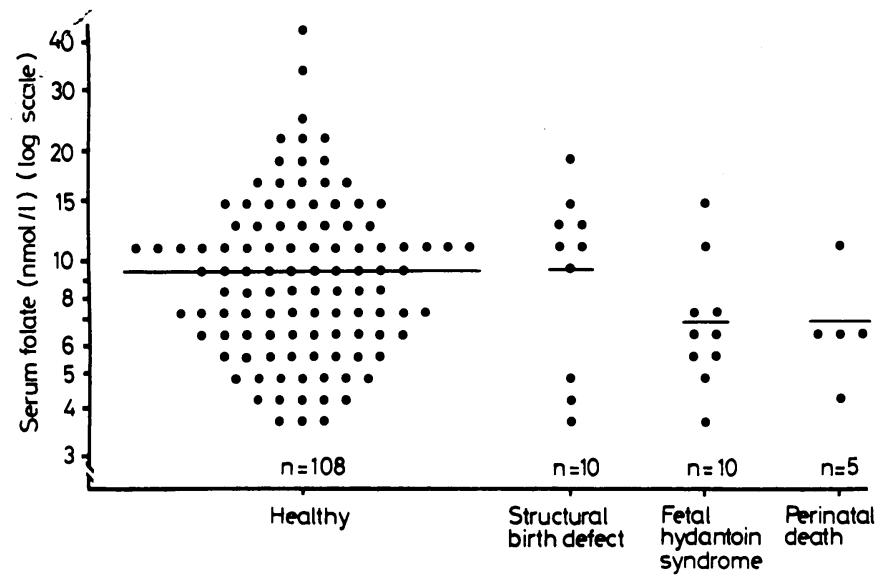

FIG 4-Relation between maternal serum folate concentrations and fetal outcome. Serum folate is given as the first measured value in pregnancy in 133 cases. The child with both a structural birth defect and fetal hydantoin syndrome is included in the former group. There were no anomalies among the 17 children excluded from this analysis. One way analysis of variance: $F_{3: 129}-1 \cdot 8, p=0 \cdot 15$. Differences between groups are not significant.

\section{Discussion}

Although our findings show an inverse correlation between maternal serum concentrations of phenytoin or phenobarbitone and serum folate concentrations, the folate concentrations usually remained well within the normal range. There were no cases of maternal tissue folate deficiency or fetal damage attributable to low maternal serum folate concentrations. Our patients were all primarily well nourished, and therefore we cannot exclude the possibility that folate deficiency states encountered elsewhere might interfere with fetal development. In our series there were no cases of neural tube defects. Neural tube defect is relatively rare in Finland, and even a several-fold increase in its occurrence could be missed in a study of this size. We cannot thus contribute much to the question of the possible relation between folate and central nervous system anomalies. ${ }^{11}$

Our results suggest that a low dose of supplementary folate (100 to $1000 \mu \mathrm{g}$ daily) throughout pregnancy, as widely recommended for pregnant women in general, ${ }^{1}$ is sufficient to prevent folate deficiency even in epileptic women despite the folate-antagonising properties of antiepileptic drugs. Serum folate concentration decreases progressively during normal pregnancy if no folate pills are taken. ${ }^{12}$ This decrease might be accentuated in the presence of phenytoin or phenobarbitone. We therefore suggest that women receiving either drug should take folate pills during (and preferably before) pregnancy to ensure an adequate supply for the fetus.

We found no association between serum folate concentrations and the number of epileptic seizures in pregnancy. It thus seems that a daily dose of 100 to $1000 \mu \mathrm{g}$ of oral folate does not impair control of seizures as reported for higher doses $(5 \mathrm{mg}$ and more). ${ }^{3}$

In agreement with the findings of an investigation on nonpregnant epileptics ${ }^{13}$ our results showed no association between serum folate concentrations and treatment with carbamazepine. Carbamazepine may not, however, be safer than the other antiepileptic drugs during pregnancy, as its use was associated with a smaller than expected infant head circumference in our series. ${ }^{14}$

Although the ideal treatment of epilepsy during pregnancy remains controversial, ${ }^{16}{ }^{16}$ the best approach today is probably to continue giving the patient her previous drug(s), preferably using monotherapy,,$^{15}$ and to keep the serum concentrations as low as possible to reduce fetal exposure, while retaining an adequate control of seizures. Drug concentrations below the conventional "therapeutic" concentrations often suffice in pregnancy. Monitoring of the serum concentrations of antiepileptic drugs during pregnancy is currently recommended, ${ }^{18}$ and monitoring of the folate state seems advisable, at least in patients with high serum concentrations of phenytoin or phenobarbitone.

\section{References}

1 Kitay DZ. Folic acid and reproduction. Clin Obstet Gynaecol 1979;22: 809-17.

2 Anonymous. Folates and the fetus [Editorial]. Lancet $1977 ; \mathrm{i}: 462$.

s Reynolds EH. Anticonvulsants, folic acid, and epilepsy. Lancet 1973;i : 1376-8.

${ }^{4}$ Reynolds EH, Mattson RH, Gallagher BB. Relationship between serum and cerebrospinal fluid anticonvulsant drug and folic acid concentrations in epileptic patients. Neurology 1972;22:841-4.

${ }^{5}$ Longo DL, Herbert V. Radioassay for serum and red cell folate. $f$ Lab Clin Med 1976;87:138-51.

- Gutcho S, Mansbach L. Simultaneous radioassay of serum vitamin B12 and folic acid. Clin Chem 1977;23:1609-14.

${ }^{7}$ Kupferberg HJ. Quantitative estimation of diphenylhydantoin, primidone and phenobarbital by gas-liquid chromatography. Clin Chim Acta $1970 ; 29: 283-8$

- Frey H, Yrjänä T. Carbamazepine titers in epileptic patients. Scand $\mathcal{F}$ Clin Lab Invest 1970;25, suppl 113:90.

- Rose M, Johnson I. Reinterpretation of the haematological effects of anticonvulsant treatment. Lancet 1978; :1349-50.

10 Hanson JW, Myrianthopoulos NC, Sedgwick Harvey MA, Smith D. Risks to the offspring of women treated with hydantoin anticonvulsants, with emphasis on the fetal hydantoin syndrome. F Pediatr 1976;89: 662-8.

1 Anonymous. Vitamins to prevent neural tube defects [Editorial]. Lancet $1982 ; \mathrm{ii}: 1255-6$.

$12 \mathrm{Ek}$ J, Magnus EM. Plasma and red blood cell folate during normal pregnancies. Acta Obstet Gynecol Scand 1981;60:247-51.

13 Dellaportas DI, Shorvon SD, Galbraith AW, et al. Chronic toxicity in epileptic patients receiving single-drug treatment. $B r$ Med $\mathcal{f} 1982 ; 285$ : 409-10.

14 Hiilesmaa VK, Teramo K, Granström M-L, Bardy AH. Fetal head growth retardation associated with maternal antiepileptic drugs. Lancet 1981 ;ii : $165-7$.

15 Anonymous. Teratogenic risks of antiepileptic drugs [Editorial]. $\mathrm{Br} \mathrm{Med} \mathcal{F}$ $1981 ; 283: 515-6$.

16 Anonymous. Valproate and malformations. Lancet 1982 ;ii:1313-4.

17 Bardy AH, Hiilesmaa VK, Teramo K, Granström M-L. Teratogenic risks of antiepileptic drugs. $\mathrm{Br}$ Med $\mathcal{F} 1981 ; 283: 1405-6$.

18 Anonymous. Epilepsy and pregnancy [Editorial]. $\mathrm{Br} M$ ed $\mathcal{F} 1980 ; 281$ : 1087-8.

(Accepted 18 May 1983)

BEZOAR WATER-"Take of the leaves of Celandine, roots and all, three handfuls and a half, Rue two handfuls, Scordium four handfuls, Dittany of Crete, Carduus, of each one handful and a half, Zedoary and Angelica roots, of each three drams, Citrons and Lemon pills, of each six drams, Clove-gilliflowers one ounce and a half, Red Rose, Centaury the less, of each two drams, Cinnamon, Cloves, of each three drams, Venice Treacle three ounces, Mithridates one ounce and a half, Camphire two scruples, Troches of Vipers two ounces, Mace two drams, Wood of Aloes half an ounce, Yellow Sanders one dram and a half, Carduus seeds one ounce, Citron seeds six drams, let them be cut and infused in spirits of Wine, and Malaga Wine, of each three pound and a half, Vinegar of Clove-gilliflowers, Juice of Lemons, of each one pound, and distilled in a glass still in Balneo Mariae, after it is half distilled off, the residue may be strained through a linen cloath, and be reduced to the thickness of Honey, and called the Bezoartic extract."

Extracts have the same virtues with the waters they are made from, only the different form is to please the palates of such whose fancy loathes any one particular form.

This Bezoar water strengthens the heart, arteries, and vital spirits: It provokes sweat, and is exceeding good in pestilential fevers, in health it withstands melancholy and consumptions, and makes a merry, blithe, chearful creature. Of the extract you may take ten grains at a time, or somewhat more, if your body be not feverish, half a spoonful of water is sufficient at a time, and that mixed with other cordials or medicines appropriated to the disease that troubles you. (Nicholas Culpeper (1616-54) The Complete Herbal, 1850.) 